Çukurova Üniversitesi Mühendislik Fakültesi Dergisi, 36(1), ss. 11-24, Mart 2021

Cukurova University Journal of the Faculty of Engineering, 36(1), pp. 11-24, March 2021

\title{
Güneş Enerjisi Santrali için Uygun Alanların CBS Tabanlı AHP Yöntemi ile Belirlenmesi: Mersin İli Örneği
}

\author{
Esra Deniz GÜNER ${ }^{* 1}$, Senem TEKİN ${ }^{2}$, Ahmet ÇILLEK ${ }^{3}$, Müge ÜNAL ÇİLEK ${ }^{3}$ \\ ${ }^{1}$ Çukurova Üniversitesi, Mühendislik Fakültesi, Çevre Mühendisliği Bölümü, Adana \\ ${ }^{2}$ Adryaman Üniversitesi, Madencilik ve Maden Çıkarma Bölümü, Adlyaman \\ ${ }^{3}$ Çukurova Üniversitesi, Mimarlık Fakültesi, Peyzaj Mimarllğg Bölümü, Adana
}

$\ddot{\mathbf{O} z}$

Geliş tarihi: 14.12.2020 Kabul tarihi: 31.03.2021

Güneş enerji santrallerinin nihai yer seçim kriterleri çevresel, topografik, ekonomik, ve yasal mevzuatlar gibi bir çok değişkene bağlıdır. Yer seçimini etkileyen bu kriterler düşünüldüğünde, güneş enerji santrallerinin yer seçim yaklaşımları büyük yatırımlar için kritik bir konudur. Bu kriterlerin sistematik bir hiyerarşide düzenlemek zorunludur. Güneş enerjisi santrallerin yer seçiminin modern yöntemlerle seçilmesi ile ülke ekonomisine önemli bir katkı sağlanacağı düşünülmektedir. Bu doğrultuda mevcut çalışma, Coğrafi Bilgi Sistemleri (CBS) tabanlı çok kriterli bir karar verme (ÇKKV) tekniğini kullanarak Mersin İli'ndeki (Türkiye) güneş enerjisi santralleri için uygun yerlerin belirlenmesi amaçlamaktadır. Çevresel, ekonomik ve topografik kriterleri ağıllıklandırmak ve potansiyel alanların uygunluğunu değerlendirmek için analitik hiyerarşi yöntemi (AHP) uygulanmıştır. Sonuç olarak, çalışma alanının güneş enerjisi alanları için sahile yakın Tarsus, Yenişehir, Erdemli, Silifke, Anamur ilçelerinin ve çevresi alanların yüksek uygunluk düzeyine sahip olduğu tespit edilmiştir. Çalışma alanının kuzeydoğusunda yer alan Çamlıyayla ilçesinin ise güneş enerji santralleri için az uygun alan olarak bulunmuştur.

Anahtar Kelimeler: Yer seçimi, Güneş enerjisi, Çok kriterli karar verme, Analitik hiyerarşi süreci, CBS

\section{Determination of Suitable Areas for SolarPower Plant with GIS Based AHP Method: Mersin Province Example}

\begin{abstract}
The location selection criteria for solar power plants depedns on many variables such as environmental, topographic, economic impacts and legal regulations. Considering these criteria that affect the location selection, location approach of solar power plants is a critical issue for large investments. It is imperative to organize these criteria in a systematic hierarchy. It is thought that a significant contribution will be made to the country's economy by choosing the location of solar power plants with modern methods. Existing work in this direction, GIS-based (Geographic Information Systems) multi-criteria decision making (MCDM) using the technique in Mersin (Turkey) aims to select suitable location for solar power plants. Analytical hierarchy process (AHP) was used to weight the criteria and evaluate potential sites. As a result, Tarsus, Yenişehir, Erdemli, Silifke, Anamur districts close to the seashore and their surrounding areas were determined to be suitable for the solar energy fields of the study area. While Çamliyayla district, which is located in the northeast, is found to be less suitable for solar power plants.
\end{abstract}

Keywords: Location selection, Solar power, Multi-criteria decision making, Analytic hierarchy process, GIS

*Sorumlu yazar (Corresponding author): Esra Deniz GÜNER, eguner@cu.edu.tr 


\section{GIiRiş}

Enerji, insanlığın temel gereksinimlerinden birisidir. Sanayi devrimi ile birlikte yaşam standartlarının yükselmesi, çoğalan nüfusun mal ve enerji ihtiyacını karşılama gereksinimini ortaya çıkarmıştır. Fosil yakıtlar, yenilenebilir kaynaklar ve nükleer kaynaklar olmak üzere üç temel kategoride enerji kaynakları hızlı enerji tüketimini karşılamak için kullanılmıştır. Geçmişten beri en çok kullanılan enerji kaynağı fosil yakıtlar olmasına rağmen kaynakların kisitlı olması ve olumsuz çevresel etkilerinin bulunmasından dolayı, insanları alternatif enerji kaynaklarını kullanmaya yönlendirmiştir. Teknolojideki gelişmeler ile birlikte yenilenebilir enerji, sınırsız kaynaklarının tekrar tekrar kullanılması (güneş enerjisi, rüzgâr enerjisi, biyokütle enerjisi, jeotermal enerji, vb.) ile sürdürülebilir enerji üretimi açısından ön plana çıkmıştır [1-3]. Özellikle 21. yüzyılda fosil yakıtların hızla artan iklim değişikliği ve küresel 1sınma sorunlarının temel sebeplerinden biri olarak gösterilmesi temiz enerji üretimine olan ihtiyacı ortaya çıkarmıştır [4-6].

Güneş enerjisi bol, sürekli ve dışa bağımlı olmaması ile oldukça değerli yenilenebilir enerji kaynaklarındandır. Güneş enerjisi santralleri (GES), güneş 1şınımını doğrudan fotovoltaik ile veya dolaylı olarak konsantre güneş enerjisi ile elektriğe dönüştürür. Güneş enerjisi üretimi sürdürülebilir olması, kolay erişilebilirliği, çevresel etkilerinin çok az olması ve güneş enerjisi üretim tesislerine devlet teşviklerinin olması bakımından diğer enerji kaynaklarından avantajlıdır [7]. $\mathrm{Bu}$ avantajları ile fotovoltaik güneş enerjisi, dünyanın gelecekteki enerji talebini sürdürülebilir bir şekilde karşılamak için en iyi seçeneklerden biri olarak görülmektedir [8-14]. Uluslararası Enerji Ajansı (UEA), güneş enerjisinin 2050 yılına kadar \%20-25 artacağını böylece fotovoltaik ve dolaylı olarak konsantre güneş enerjisi sistemleri ile 9000 TWh elektrik üretmenin mümkün olacağını belirtmiştir. $\mathrm{Bu}$ temiz elektrik miktarı $\mathrm{CO}_{2}$ emisyonlarının yılda yaklaşık 6 milyar ton azaltılmasına katkıda bulunabileceği tahmin edilmektedir [4-6].
Türkiye zengin kaynakları ile yüksek yenilenebilir enerji potansiyeline sahiptir [15,16]. Türkiye'nin 2023 'te kurulu gücünün 110.000 ila $130.000 \mathrm{MW}$, ve elektrik tüketiminin 500 milyar kWh olmas1 tahmin edilmektedir [17]. Türkiye hükümeti 2014 yılında Ulusal Yenilenebilir Enerji Eylem Planını açıklamıştır. Bu eylem planına göre, 2023 yılına kadar enerji verimliliğini artırmak ve yenilenebilir enerji üretiminin toplam payını \%30'a çıkarmayı hedeflemektedir [18-20]. Türkiye'de baskın yenilenebilir enerji kaynağı, tahmini 48.000 MW'a varan bir kurulumla rüzgar enerjisi olarak kabul edilebilir. Toplam ülke elektrik üretiminin \%6,6'sina denk olan 7.005 MW enerji rüzgar enerjisinden tedarik edilmektedir. Güneş enerjisinin ise toplam kurulu gücü 5.063 MW (toplam ülke elektrik üretiminin \%2,6'sı) ile önemli bir yenilenebilir kaynağıdır [18-20]. Ancak, güneş enerjisi potansiyeli kullanılarak elektrik üretiminin sadece 643 kTOE olmuştur [18-20].

Güneş enerjisi santrallerinin yer seçimi güneş enerjisi projelerinin inşaat, kurulum ve işletme basamaklarını kapsayan hayati bir stratejik karardır. Ayrıca nihai güç üretiminde, santral verimliliğinde ve elektrik üretim maliyetinde önemli bir rol oynamaktadır [3]. Güneş potansiyeli sergileyen yerlerin güneş enerjisi santralleri kurmak için en uygun alanlar olması gerekmez, çünkü saha seçimini etkileyen birçok kriterler vardır [9,21-23]. Güneş enerjisi santrallerinin yer seçimi, ekonomik, sosyal, çevresel ve kültürel pek çok unsuru içermektedir. $\mathrm{Bu}$ nedenle, güneş enerjisi santrallerinin alan seçimi, genel performansı en üst düzeye çıkarmak için güneş enerjisi endüstrisi yöneticileri için en vazgeçilmez konulardan biri haline gelmiştir. $\mathrm{Bu}$ sorunun üstesinden gelmek için, coğrafi bilgi sistemleri (CBS) tabanlı çok kriterli karar verme teknikleri (ÇKKV) (multi-criteria decision analysis-MCDA) enerji planlama problemlerinde etkili bir şekilde kullanılmıştır. Ayrıca ÇKKV pek çok farklı unsuru bir arada değerlendirilerek güneş santralleri için uygun yer seçim kararının verilmesinde plancılar, tasarımcilar, mühendisler ve pek çok meslek grubunu bir arada bulundurularak karar vericilere planlama ve yönetim aşamasında yol gösterici olmaktadır $[8,9,11,24,25]$. 
Çalışmada CBS tabanlı çok kriterli karar verme yöntemlerinden biri olan AHP kullanılarak Mersin İli için güneş enerji santrali kurulabilecek uygun alanların tespit edilmesi amaçlanmıştır. Bu önemli stratejik karar verme süreci için çalışmada izlenecek ve dikkat edilmesi gereken adımlar şunlardır: (1) güneş enerjisi santralleri için uygun yer seçim kararının verilmesine yardımcı olabilecek faktör ve kısıtlayıcılar ile bunların eşik değerleri belirlenmesi, (2) kriterlerin analitik hiyerarşi süreci (Analytic hierarchy process-AHP) ile ağırlıklarının belirlenmesi, (3) Bulanık mantık (Fuzzy logic) ile kriterlerin standardize edilmesi, (4) kriterler aracılığ çakıştırılarak uygun alanların belirlenmesidir (Şekil 1). Bu çalışma sonuçlarının enerji üretimi ile ilgili plan ve politikalara altlık veri oluşturması, çalışma yönteminin ise yerel yönetimlere, hükümete ve yatırımcılara uygun yer seçim kararının verilmesinde yardımcı olması beklenmektedir.

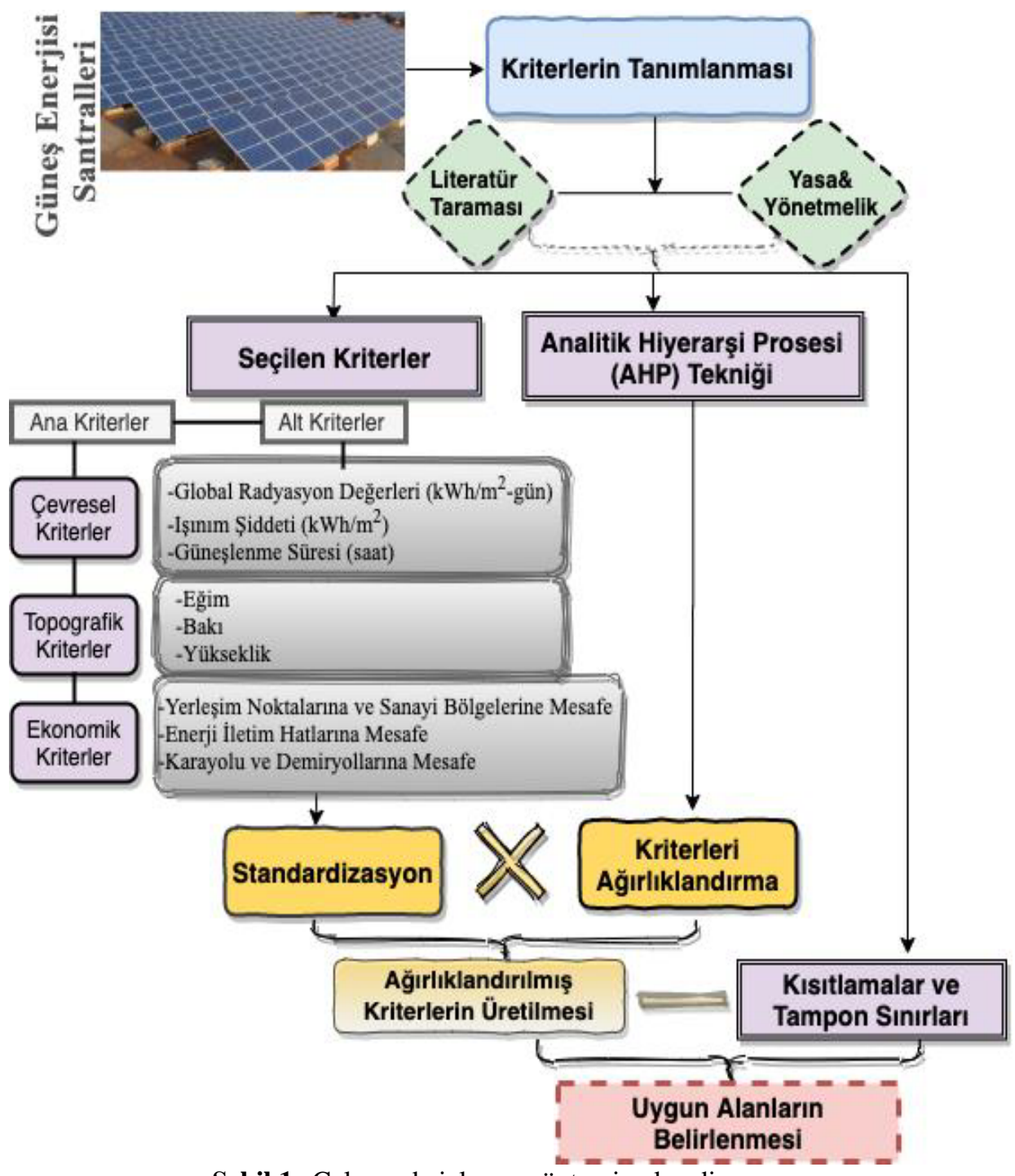

Şekil 1. Çalışmada izlenen yöntemin akış diyagramı 


\section{MATERYAL VE METOT}

\section{1. Çalışma Alanı}

Türkiye'nin güneyinde Akdeniz Bölgesi sınırları içerisinde yer alan Mersin İli çalışma alanı olarak seçilmiştir (Şekil 2). Bir liman kenti olan Mersin, $36-37^{\circ}$ kuzey enlemleri ve $33-35^{\circ}$ doğu boylamları arasında yer almaktadır. Kentin toplam yüzey alanı15.843 $\mathrm{km}^{2}$ olup Türkiye'nin en kalabalık onuncu şehridir ve 2019 yılı itibariyle, 1.814.000 nüfusa sahiptir. Çalıșma alanı güneyde Akdeniz, kuzeyde Doğu Toros Dağları ile sınırlandırılmıştır. $\mathrm{Bu}$ yüzden kentin topoğrafyası güneyden kuzeye gidildikçe değişkenlik göstermektedir. Alanda en düşük kot deniz seviyesinde yer alırken, en yüksek kot 3500 m yükseklikte yer almaktadır. Çalışma alanında Akdeniz'e yakın ovalarda eğim \%0-2 düze yakın eğime sahip iken, Doğu Toros dağlarına gidildikçe \%20-30 dik eğime sahip yamaçlar bulunmaktadır. Kent iklimi kıyıda denizel etkide, kıyıdan uzaklaştıkça karasal iklimin etkisi altında kalmaktadır. Genel olarak kentte tipik sicak ve 1lıman astropikal iklim görülmektedir. Yaz ayları sıcak ve aşırı nemli kış ayları ılık ve yağışııdır (yıllık yağı̧̧ ortalaması $1096 \mathrm{~mm}$ ). Yaz aylarında ortalama sicaklık $33^{\circ} \mathrm{C}$, hakim rüzgar yönü Güney-Güneybat1, rüzgar hızı $3 \mathrm{~km} / \mathrm{s}$ ve ortalama nem \%57'dir. Kentin enerji üretimi 3.335.544 MWh/y, enerji tüketimi ise 5.157.530 MWh/y'dir [14,20]. Çalışma alanı olarak Mersin kentinin seçilme sebepleri ise:

- Y1l boyunca güneşlenme süresinin diğer bölgelere göre yüksek olması,

- Alanda güneş, rüzgar vb. yenilenebilir enerji santrallerinin bulunmasından dolayı bölgenin yenilenebilir enerji santral potansiyelinin olmas1,

- Yeni enerji tesisleri için çalışma alanının iklimsel ve topoğrafik özelliklerinin elverişli olması,

- Türkiye 11. kalkınma planında Çukurova bölgesinin enerji koridoru olarak görülmesi ve çalışma alanının bu koridorda yer alması olarak sıralanabilir.

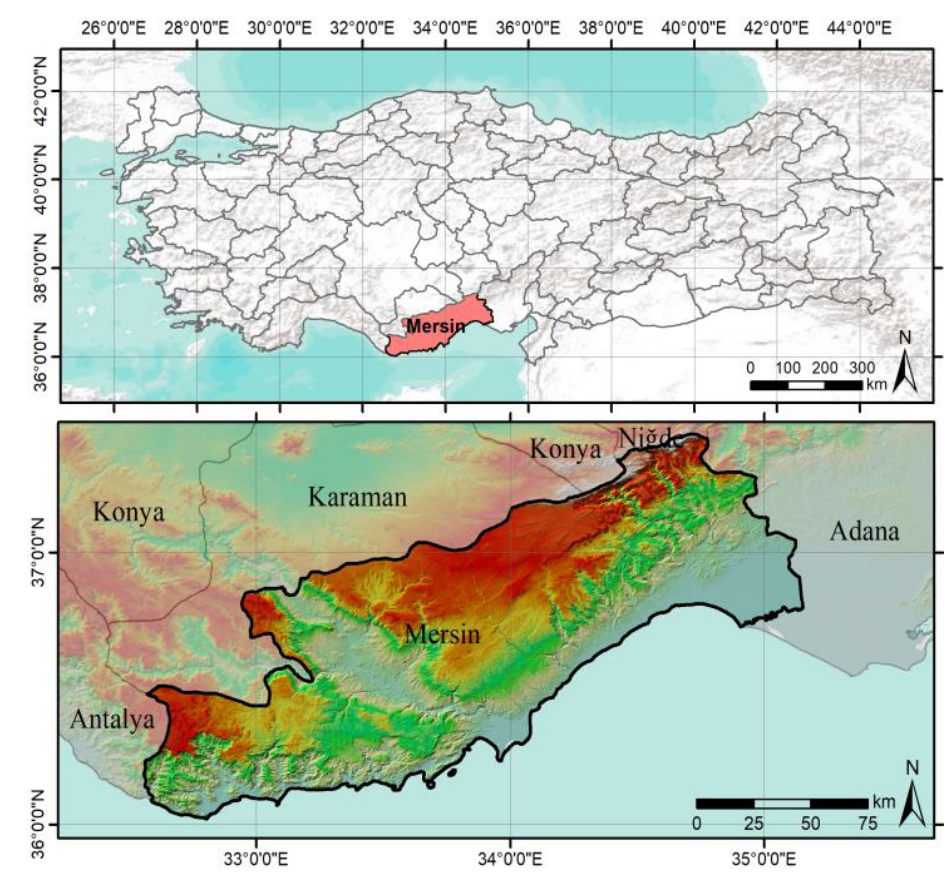

Şekil 2. Çalışma alanı Mersin İli'nin konumu 


\subsection{Yöntem}

Çalışmada yeni tesis edilmesi planlanan güneş enerjisi santralleri için en uygun bölgelerin belirlenmesi CBS tabanlı bulanık mantık ve analitik hiyerarşi süreci (AHP) tekniğinin uygulanması aracılığıyla olmuştur.

Aşama 1: Yöntemin uygulanmasında birinci aşama güneş enerjisi santrallerinin kurulumunu kısıtlayan veya teşvik eden kriterlerin belirlenmesidir. Kriterleri belirlemek için bu konuda yapılmış ulusal ve uluslararası literatürlerden, yasa ve yönetmeliklerden ve uzman görüşlerinden faydalanılmıştır. Son on yılda yapılan çalışmalar incelendiğinde, güneş enerjisi santralleri yer seçimi ile ilgili ekonomik, teknik, çevresel, sosyal ve kültürel pek çok kriterin değerlendirildiği gözlemlenmiştir (Çizelge 1). Bu kriterler yapılan plan, proje ve yerel yönetimlerin belirlemiş oldukları politika önceliklerine göre çalışmadan çalışmaya farklılık göstermektedir.

Çizelge 1. Ulusal ve uluslararası literatürde yer alan kriterler

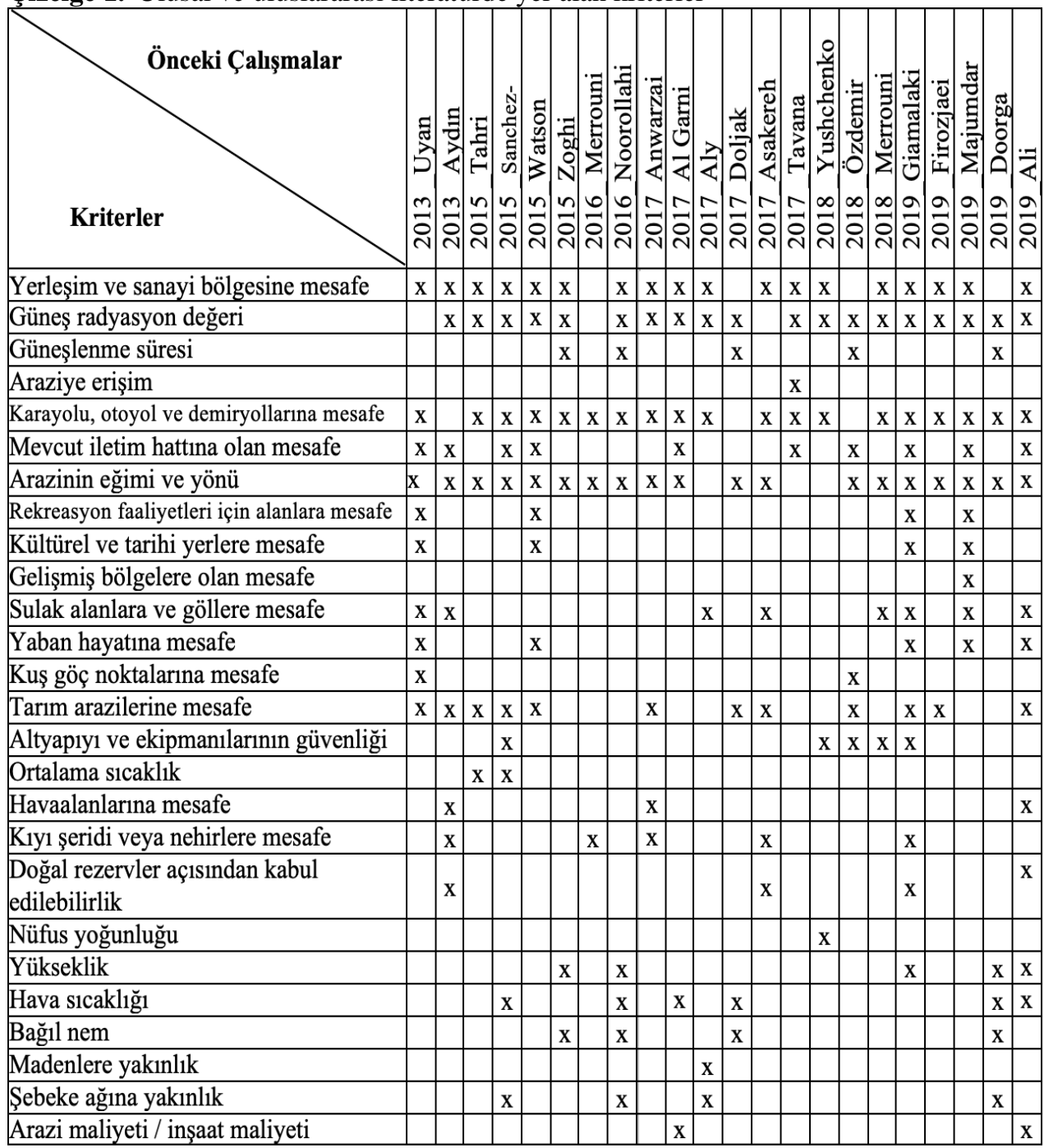


Bu çalışmada ise değerlendirme kriterleri iklimsel, topografik ve ekonomik olmak üzere üç ana kriter altında toplanmış ve toplam 9 alt kriter güneş enerjisi santralleri için uygun alanların değerlendirilmesinde kullanılmıştır (Çizelge 2). İklimsel kriterler, güneş enerjisi santralinin kurulmasında gerekli olan iklim parametrelerini içermektedir. Teknik kriterler, güneş ışınımının miktarı ve hava sicaklığı, bağıl nem, yağış kriterlerinin ortalamasını içerir. Ekonomik kriterleri, güneş enerjisi santrallerinin yerleştirilmesinin proje maliyeti üzerindeki etkisini ifade etmektedir.

Çizelge 2. Sınırlayıcı veya teşvik edici kriterlerin hiyerarşik yapısı

\begin{tabular}{|c|c|c|}
\hline $\begin{array}{l}\text { ANA } \\
\text { KRITERLER }\end{array}$ & $\begin{array}{l}\text { ALT } \\
\text { KRITERLER } \\
\end{array}$ & SINIRLAYICI VEYA TEŞVIK EDICI ÖZELLÍKLER \\
\hline \multirow{3}{*}{$\begin{array}{l}\text { ÇEVRESEL } \\
\text { FAKTÖRLER }\end{array}$} & $\begin{array}{c}\text { Global } \\
\text { radyasyon değeri } \\
\left(\mathrm{kWh} / \mathrm{m}^{2} \text {-gün }\right)\end{array}$ & $\begin{array}{l}\text { Global radyasyon değeri (GHI), güneş enerjisi proje } \\
\text { geliștirmelerinde temel karar kriteridir }[8,22,24] \text {. GHI, sistemden } \\
\text { elektrik çıkışını büyüklüğünü belirler dolayısyla da santrallerin } \\
\text { verimliliğini etkiler. Bu değerin } 1800 \mathrm{kWh} / \mathrm{m}^{2} / \mathrm{yll} \text { 'dan az olan } \\
\text { arazileri uygun bulunmazken ve bu eşik değerinden daha yüksek } \\
\text { olan alanlar çok kriterli analizler kullanılarak sinıflandırmıştır [8, } \\
\text { 26]. }\end{array}$ \\
\hline & $\begin{array}{l}\text { Güneş 1şınımım } \\
\text { şiddeti } \\
\left(\mathrm{kWh} / \mathrm{m}^{2}\right)\end{array}$ & $\begin{array}{l}\text { Güneş 1şınımı, birim alan başına güçtür (metrekare başına watt, } \\
\left.\mathrm{W} / \mathrm{m}^{2}\right)[12,27,28] \text {. Iran'da } 500 \mathrm{Watt} / \mathrm{m}^{2} \mathrm{l} \text { lik güneş radyasyonunun } \\
\text { varlığını ideal kabul etmiştir [13]. Türkiye'nin batısında bulunan } \\
\text { güneş enerjisi tesisatları için min } 4.5 \mathrm{kWh} / \mathrm{m}^{2} / \text { gün güneş } \\
\text { radyasyonu değerinin varlığ uygun kabul edilmiştir [29]. }\end{array}$ \\
\hline & $\begin{array}{l}\text { Güneşlenme } \\
\text { süresi } \\
\text { (saat) }\end{array}$ & 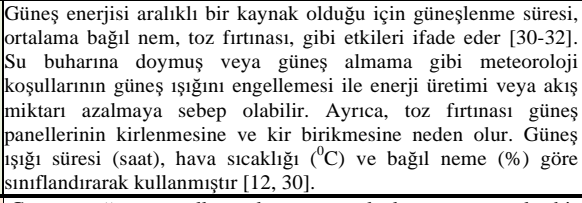 \\
\hline \multirow{3}{*}{$\begin{array}{l}\text { TOPOGRAFIK } \\
\text { FAKTÖRLER }\end{array}$} & Eğim & 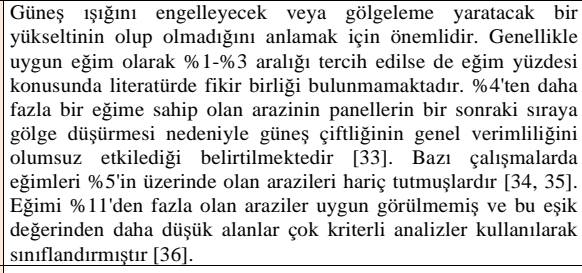 \\
\hline & Bak1 yönü & $\begin{array}{l}\text { Güneş panellerinin yönlendirmesi gelen güneş radyasyonuna } \\
\text { maruz kalmanın belirlenmesinde önemlidir. Güney yarımkürede } \\
\text { yer alan Mauritius'da yapılan bir çalışmada, güneş panellerinin } \\
\text { güneşten gelen enerjiyi en üst düzeye çıkarmak için coğrafi } \\
\text { kuzeye doğru yönlendirilmesi gerektiğini belitmiştir [12]. Kuzey } \\
\text { yarım kürede yer alan Türkiye'de ise yapılan çalışmalarda Güney } \\
\text { bakı yönü uygun yeri belirlemede tercih edilmektedir [9, 21-23]. }\end{array}$ \\
\hline & Yükseklik & $\begin{array}{l}\text { Yüksek rakımda nadir flora ve fauna türlerine rastlanması, yol ve } \\
\text { elektrik iletim ağını seyrek olması nedeniyle yükseklik kriteri } \\
\text { önemlidir [37, 38]. Önceki çalısmalarda, güneş enerjisi için } \\
\text { yüksek rakım önerilmez [8,39]. Literatürde, deniz seviyesinden } \\
\text { yüksekliğe, } 2000 \text { m'lik [22] veya } 200 \mathrm{~m} \text { mak. [8] uygun olarak } \\
\text { görmektedir. }\end{array}$ \\
\hline \multirow{3}{*}{$\begin{array}{l}\text { EKONOMIK } \\
\text { FAKTÖRLER }\end{array}$} & $\begin{array}{l}\text { Yerleşim ve } \\
\text { sanayi } \\
\text { noktalarına } \\
\text { mesafe }\end{array}$ & $\begin{array}{l}\text { Kentsel veya kırsal alanların yakınında güneş enerjisi santrali inşa } \\
\text { edilmesi kentsel ve nüfus gelişimi üzerinde olumsuz çevresel } \\
\text { etkilere neden olabilir [40-42]. Ancak güvenlik, bakım-onarım, } \\
\text { temizlik gibi süreklilik arz eden faaliyetlerin yürütülebilmesi için } \\
\text { işgücü erişimine ve bunlara ilişkin harcamaları en aza indirmek } \\
\text { için, avantaj sağliyabilir. Literatürde, güneş enerjisi santralleri için } \\
\text { uygun bir yerleşim yeri yerleşim alanlarından en az } 500 \text { m uzaklık } \\
\text { uygun olarak kabul görmektedir [43, 44]. }\end{array}$ \\
\hline & $\begin{array}{c}\text { Enerji nakil } \\
\text { hatlarına mesafe }\end{array}$ & $\begin{array}{l}\text { Üretilen elektriği şebekeye kolayca enjekte etmek ve iletim } \\
\text { kayıplarını en az seviyeye indirmek için saha yüksek voltaj } \\
\text { kablolarına yakın olmalıdı }[45,46] \text {. Bu nedenle, iletim güç } \\
\text { hatlarının yakınında bulunan alanlara daha yüksek öncelik } \\
\text { değerleri atanmalıdır. Büyük GES projelerinde yer seçiminde } \\
\text { şebeke ağına en fazla } 10 \mathrm{~km} \text { uzaklık olması verimlilik için tercih } \\
\text { edilmektedir [22,47, 48]. }\end{array}$ \\
\hline & $\begin{array}{l}\text { Ulaşım ağına } \\
\text { mesafe }\end{array}$ & $\begin{array}{l}\text { Ana yollara yakınlık, güneş enerjisi santralleri inşa ve kurulum } \\
\text { aşamasındaki maliyetleri etkili bir şekilde azaltabilir. Bu nedenle, } \\
\text { ana yollara daha yakın konumlara daha yüksek bir öncelik } \\
\text { verilmelidir }[25,45,46] \text {. }\end{array}$ \\
\hline
\end{tabular}


Aşama 2: Çalışmanın ikinci aşaması belirlenen kriterlerin standardizasyonunun bulanık mantık (Fuzzy Logic) aracılığı ile yapılmasıdır. Buradaki temel amaç farklı ölçü değerlerine sahip kriterlerin ortak bir birime getirilmesidir. Bu yaklaşımda her bir Fuzzy seti fonksiyonu değerlendirilerek bu setlere ait her bir piksel için değerlendirilme yapılır. Sigmoidal, J-shaped ve doğrusal fonksiyonlar değer ölçeğindeki en yüksek ve en düşük değerlerden elde edilen kontrol noktaları ile biçimlendirilirler. İlk nokta fonksiyonun sıfırdan yükselmeye başladığı alanı temsil etmektedir. İkinci nokta fonksiyonun 1'e ulaştı̆̆1 yerdir. Üçüncü nokta fonksiyonun yeniden 1'den aşağ doğru düşmeye başladığı alan ve 4 . nokta ise fonksiyonun 0 değerine geri döndüğü alandır. The Sigmoidal ("s-shaped") biçim Fuzzy seti teorilerinde en çok kullanılan fonksiyondur ve kosinüs fonksiyonu kullanılarak üretilmiştir. Aşağıda Fuzzy fonksiyonun ihtiyaç duyduğu 4 adet kontrol noktasına ait değerler verilmiştir. Bunlar sigmoidal eğri üzerinde a, b, c, d olarak Şekil 3'te gösterilmiştir:

$\mathrm{a}=$ fonksiyonun ' 0 ' in üzerine çıktığı nokta

$\mathrm{b}=$ fonksiyonun ' 1 'e ulaştı̆ğ nokta

$\mathrm{c}=$ fonksiyonun ' 1 ' den azalmaya başladığı nokta

$\mathrm{d}=$ fonksiyonun '0'olduğu nokta
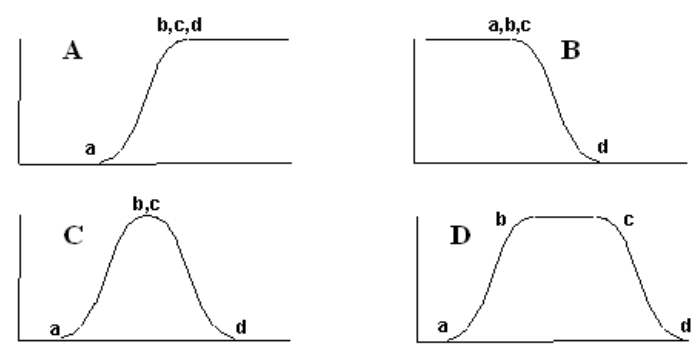

Şekil 3. Sigmoidal fonksiyonlar, (A) Monoton olarak artan, (B) Monoton olarak azalan, (C) ve (D) Simetrik [49]

Sigmoidal fonksiyonuna ait üyeler monoton olarak artan, monoton olarak azalan, simetrik (üst sol, üst sağ, alt sol ve alt sağ) şekilde olabilmektedir. Fonksiyonun monoton olarak arttığı durumlarda $b$, c, d kontrol noktaları için verilen değerler aynıdır. Aynı şekilde fonksiyonun monoton olarak azaldığ durumlarda ise a, b, c kontrol noktaları aynı değere sahiptir. Fuzzy uygulaması ile aynı zamanda, Boolean yaklaşımı dişında (0-1, uygun değiluygun), yumuşatılan sinırlar da (uygun olabilir) oluşturulmaktadır [49].

Aşama 3: Çalışmanın son basamağı ise analitik hiyerarşi sürecini içermektedir. Analitik Hiyerarşi Süreci (AHP) ilk olarak 1968 yılında Myers ve Alpet tarafından ortaya konulmuş ve 1977 yılında Saaty tarafından karar verme problemlerinin çözümünde kullanılabilir bir yöntem olarak geliştirilmiştir. AHP, karar almada nicel ve nitel ölçütleri değerlendirebilen, grup veya bireyin tercihlerini, deneyimlerini, sezgilerini, bilgilerini, yargılarını ve düşüncelerini karar sürecine dahil edebilen, karmaşı $1 \mathrm{k}$ problemlerin hiyerarşik bir yap1 içinde ele alınarak çözülmesini sağlayan birçok kriterli karar verme yöntemdir.

AHP modelinin uygulanması hedef belirleme ve ardından ana kriterler ve alt kriterlerin belirlenmesi ile başlar. AHP yönteminde çalışmanın amacına göre uzmanlara ana kriter ve alt kriterlerin ikili karşılaştırmalarını yapılması istenir. $\mathrm{Bu}$ karşılaştırmalar Saaty tarafından tanımlanan 9değer ölçeğine göre puanlanır [50]. Güneş enerji santrallerinin seçiminde kriterler arasında ikili karşılaştırma matrisi (Ax) oluşturulur. 9-değer ölçeğinde kriterler arasındaki önem 1-9 arasında belirtilerek, önce ana kriterler ve sonrasında alt kriterlere göre karar seçeneklerinin karşılaştırıldığı matrisler oluşturulur (Çizelge 3). Karşılaştırma matrisleri köşegen elemanları 1 olan bir kare matristir.

Çizelge 3. AHP yöntemi karşıllaştırma ölçeği

\begin{tabular}{|c|l|l|}
$\begin{array}{c}\text { Önem } \\
\text { Derecesi }\end{array}$ & Tanımı & Açılama \\
\hline 1 & $\begin{array}{l}\text { Eşit öneme } \\
\text { sahip }\end{array}$ & Her iki kriter eşit değerde önemli \\
\hline 3 & Biraz önemli & $\begin{array}{l}\text { Bir kriter diğer kritere göre biraz } \\
\text { önemli }\end{array}$ \\
\hline 5 & Fazla önemli & $\begin{array}{l}\text { Bir kriter diğer kritere göre çok } \\
\text { daha önemli }\end{array}$ \\
\hline 7 & $\begin{array}{l}\text { Çok fazla } \\
\text { önemli }\end{array}$ & $\begin{array}{l}\text { Bir kriter diğer kritere göre } \\
\text { kesinlikle çok daha önemli }\end{array}$ \\
\hline 9 & $\begin{array}{l}\text { Aşın } \\
\text { derecede } \\
\text { önemli }\end{array}$ & $\begin{array}{l}\text { Bir kriter diğer kritere göre son } \\
\text { derecede önemli }\end{array}$ \\
\hline $2,4,6,8$ & Bu değerler ise ara değerleri gösterir. \\
\hline
\end{tabular}




\section{BULGULAR}

Çalışmada CBS ve çok kriterli analizlerden birisi olan AHP yöntemi kullanılarak güneş enerji santralleri için uygun alanların belirlenmesi hedeflenmiştir. Çevresel, topografik ve ekonomik ana kriterler altında 9 alt kriter önceki çalışmalar ve çalışma alanının özelliklerine göre belirlenmiştir. Belirlenen kriterler bulanık mantık yöntemi ile ortak birim olan 0-1 arasında standardize edilmiștir. Her bir kriter için sigmodial, j-shaped ve monoton artan veya azalan fuzzy fonksiyonlarında kontrol noktaları belirlenmiştir. Ana ve alt kriterler AHP yöntemi ile güneş enerjisi santrali uygunluğu için kriter ağırlıkları hesaplanmıştır. Bu konuda uzman 20 kişi tarafından ikili karşılaştırma anketi uygulanmış ve sonuçta her bir kriterin güneş enerjisi santrali için uygun alan belirlenmesindeki ağırlık katsayısı hesaplanmıştır (Çizelge 4).

Çizelge 4. Kriterlerin ikili karşılaştırma matrisi

\begin{tabular}{|c|c|c|c|c|c|c|}
\hline Ana kriterler & Çevresel & Topografik & Ekonomik & $\begin{array}{c}\text { Ağırlık } \\
\text { Katsayısı }\end{array}$ & & \\
\hline Çevresel & 1,00 & 2,50 & 4,75 & 0,60 & & \\
\hline Topografik & 0,40 & 1,00 & 3,75 & 0,30 & & \\
\hline Ekonomik & 0,21 & 0,27 & 1,00 & 0,10 & & \\
\hline Çevresel Alt Kriterler & $\begin{array}{l}\text { Küresel yatay } \\
\text { 1şıma }\end{array}$ & $\begin{array}{l}\text { Güneş } \\
\text { 1şınımı }\end{array}$ & $\begin{array}{l}\text { Güneşlenme } \\
\text { süresi }\end{array}$ & $\begin{array}{c}\text { Ağırlık } \\
\text { Katsayısı }\end{array}$ & Fuzzy fonksiyonu & Kontrol noktalart \\
\hline $\begin{array}{l}\text { Küresel radyasyon değeri } \\
\left(\mathrm{W} / \mathrm{m}^{2}\right)\end{array}$ & 1,00 & 2,83 & 3,00 & 0,59 & Monoton artan & $\begin{array}{c}a=3 \\
b, c, d=5\end{array}$ \\
\hline $\begin{array}{l}\text { Güneş 1şınım şiddeti } \\
\left(\mathrm{W} / \mathrm{m}^{2}\right)\end{array}$ & 0,35 & 1,00 & 1,83 & 0,25 & Monoton artan & $\begin{array}{c}a=3,5 \\
b, c, d=5\end{array}$ \\
\hline $\begin{array}{l}\text { Yillık toplam güneşlenme } \\
\text { süresi (saat) }\end{array}$ & 0,33 & 0,55 & 1,00 & 0,16 & Monoton artan & $\begin{array}{c}a=2150 \\
b, c, d=2650\end{array}$ \\
\hline Topografik Alt Kriterler & Eğim & Bakı & Yükseklik & $\begin{array}{c}\text { Ağırlık } \\
\text { Katsayısı }\end{array}$ & Fuzzy fonksiyonu & Kontrol noktalarl \\
\hline Eğim (\%) & 1,00 & 0,77 & 2,05 & 0,35 & Monoton azalan & $\begin{array}{c}a, b, c=3 \\
d=10\end{array}$ \\
\hline Bakı yönü $\left(^{\circ}\right)$ & 1,30 & 1,00 & 3,33 & 0,49 & Simetrik & $\begin{array}{c}a=0 \\
b, c=180 \\
d=360\end{array}$ \\
\hline Yükseklik (m) & 0,49 & 0,30 & 1,00 & 0,16 & Monoton azalan & $\begin{array}{c}a, b, c=500 \\
d=2000\end{array}$ \\
\hline Ekonomik Alt Kriterler & $\begin{array}{c}\text { Yerleşim ve } \\
\text { endüstri yakınlık }\end{array}$ & $\begin{array}{c}\text { Enerji nakil } \\
\text { hatlarına } \\
\text { yakınlık }\end{array}$ & $\begin{array}{l}\text { Ulaşım ağına } \\
\text { yakınlık }\end{array}$ & $\begin{array}{l}\text { Ağırlık } \\
\text { Katsayısı }\end{array}$ & Fuzzy fonksiyonu & Kontrol noktalarl \\
\hline $\begin{array}{l}\text { Yerleşim ve endüstri } \\
\text { mesafe }(\mathrm{km})\end{array}$ & 1,00 & 1,01 & 1,46 & 0,37 & Simetrik & $\begin{array}{c}a=2 \\
b, c=7,5 \\
d=13\end{array}$ \\
\hline $\begin{array}{l}\text { Enerji nakil hatlarına } \\
\text { mesafe }(\mathrm{km})\end{array}$ & 0,99 & 1,00 & 2,00 & 0,40 & Monoton artan & $\begin{array}{c}a=10 \\
b, c, d=20\end{array}$ \\
\hline Ulaşım ağına mesafe (km) & 0,69 & 0,50 & 1,00 & 0,23 & Monoton artan & $\begin{array}{c}a=10 \\
b, c, d=20\end{array}$ \\
\hline
\end{tabular}

Ana kriterler incelendiğinde çevresel, topografik ve ekonomik faktörler sirasıyla $\% 60, \% 30$ ve $\% 10$ ağırlığa sahip olduğu hesaplanmıştır. Çevresel faktörler, belirli bir fotovoltaik alanın potansiyel elektrik üretimini tanımladığı için en önemli kriter olarak ortaya çıkmıştır. Belirli bir alandaki yamaçların dikliğini veya yumuşaklığını ortaya çıkaran topografik kriterler ikinci sırada gelmiştir. Son sırada ise enerjinin nakli ve kullanımı açısından önemli olan ekonomik faktörler gelmektedir.

Çevresel faktörün alt kriterleri incelendiğinde global radyasyon değeri, diğer çevresel kriterlere kıyasla 0,59'luk bir ağırlığa sahip olmuştur (Çizelge 4). Böylece güneş enerjisi santralleri için yer tahmini etkileyen en önemli çevresel faktörün güneş radyasyonu olduğu tespit edilmiştir. Bunu 
sırası ile güneş radyasyonu $(0,25)$ ve güneşlenme süresi $(0,16)$ takip etmektedir.

Topografik faktörlerde ise, bakı $(0,49)$ ve eğim $(0,35)$ yüksek öneme sahip alt kriter olmuştur. Bakı kriteri ise güneş ışınlarını alış yönünü ifade ettiğinden güney bakı yönüne sahip bölgelerde hem güneşlenme süresi diğer yönlere göre daha yüksek, hem de yükssek güneş 1 şınım şiddetine sahip olacaktır. Bu yüzden güneş enerjisi santrali yer seçiminde bu bölgelere öncelik verilmesi gerekmektedir. Kuzey cepheler ise güneşlenme süresi ve açısı bakımından GES yer seçimi için uygun olmayan alanlardır. Her ne kadar yükseklik güneşlenme açısından önemli olsa da topoğrafik faktörler arasında en düşük ağırlık puanına $(0,16)$ sahip olan alt kriter olmuştur. Ayrıca dalgalı arazi yapısı gölgelenmeye sebep olmakta, kurulum sırasında inşaat sürecini zorlaştırarak maliyet artışına sebep olabileceği için bu araziler düşük tercih oranına sahiptirler.

Ekonomik faktörler çevresel ve topografik faktörler kadar ağırlığa sahip olmasa da, güneş santrallerin yapım ve işletme aşamasında önemli faktörlerden birisidir. Bu faktör altında yer alan alt kriterler neredeyse birbirleri ile eşit önem düzeyine sahiptirler. Bunlardan güneş enerji santralinin enerji nakil hatlarına yakınlığ 0,40 , yerleşim ve endüstri alanlarına yakınlık 0,37 ve ulaşım ağına yakınlık ise 0,23 ağırlık puanına sahip olmuşlardır. İlk iki faktöre yakınlık GES'ler tarafından üretilen enerjinin iletimi sırasında en az kayıba uğraması açısından önemli iken, ulaşım güzergahlarına yakınlık hem yapım hem de bakım işleri açısından önem arz etmektedir.

Çizelge 4'te verilen ana ve alt kriterlere ait ağırlık puanlarının çarpılması sonucunda her bir kriterin uygun yer seçimindeki önem düzeyi belirlenmiştir. Ayrica kriterlerin metrik ve birimsel farklılıklarının giderilmesi için uygulanan bulanık mantık yöntemi ile tüm kriterler standardize edilmiş ve uygun olan/olmayan alanlar belirlenmiştir. Tüm kriterler için belirlenen uygun alanlar ve kriterlerin ağırlık puanları doğrultusunda tüm alanların çakıştırılması sonucunda GES için uygun alanlar belirlenmiştir (Şekil 4).
Sonuçlar, Mersin İli’nin \%66'lık gibi büyük bir oranının PV geliştirme potansiyeline sahip olduğu, $\% 26$ 'lık bir bölümün orta uygunlukta olduğunu, $\% 8$ ise az uygun veya hiç uygun olmadığını göstermektedir. Uygun alanların genellikle çalışma alanının Akdeniz'e yakın ovalık kesimlerimde olduğu, kentin kuzeyinde yer alan Toros Dağlarına gidildikçe topoğrafyanın değişmesine bağlı olarak uygun alanların azaldığı gözlemlenmiştir. Fakat Mersin bölgesinin 1 şınım değerlerinin dağlık bölgelerde çok yüksek (1800-2000 kWh/m² y1l) nüfusun yoğun olarak yaşadığı sahil bölgelerinde ise $1700-1750 \mathrm{kWh} / \mathrm{m}^{2} \mathrm{y} 1 \mathrm{l}^{\prime} \mathrm{d} 1 \mathrm{r}$.

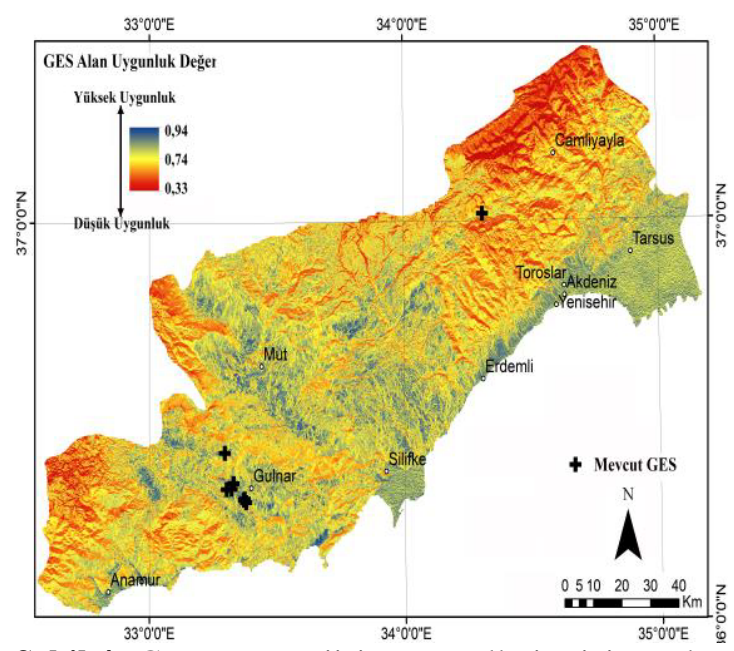

Şekil 4. Güneş enerjisi santralleri için alan uygunluk haritası

$\mathrm{Bu}$ değerin genel olarak bölgede yüksek olması santral yeri seçiminde düz alanlar kadar dağllk bölgelerde uygun noktalar olarak görülmüştür. Çalışma alanı güneyinin yeni güneş enerjisi santralleri kurulumu için daha yüksek oranda uygun olduğu belirlenmiştir. Mersin İli sınırları içerisinde Tarsus, Yenişehir, Erdemli, Silifke, Mut, Gülnar ve çevresi alanların en yüksek uygunluğa sahip olduğu ve bu bölgelerin yenilenebilir enerji potansiyelinin yüksek olduğu görülmüştür. $\mathrm{Bu}$ bölgeler arasından Tarsus, Yenişehir, Erdemli, Silifke, Anamur ilçelerinin diğer noktalara kıyasla denize yakın, düşük rakım ve düze yakın eğime sahip olmaları diğer bölgelerden daha yüksek oranda uygun alana sahip olmalarına sebep olmuştur. Dahası, bu alanlar potansiyel güneş 
enerjisi kullanımının bir yararı olarak en kalabalık bölgeler olması ve mevcut altyapı ile en yüksek enerji tüketimine sahip olmaları göze çarpmaktadır. Ayrıca, Şekil 4 incelendiğinde özellikle mevcutta Gülnar ilçesinde yoğunlaşmış bulunan mevcut güneş enerjisi santralleri ile uygunluk haritasının paralel olduğu görünmektedir. Bu mevcut tesislerin yer seçimi ve çalışma sonuçlarının örtüşmesi çalışmada kurgulanan yöntemin uygulanabilirliğini arttırmaktadır. Çamlıyayla ilçesi ve çevresinin en az uygun hatta uygun olmayan alanlar olarak tespit edilmiştir. Bunun nedeni, eğimin, yükseltinin fazla olması, bak1 yönünün bölgede kuzey olması, topografyanın değişken olması, ulaşım ağına uzak olması ve elektrik şebekesi hatlarının daha az sayıda olması olarak sıralanabilir.

\section{SONUÇLAR VE TARTIŞMA}

Enerji santrallerini için uygun yerlerin seçimi birbiriyle çelişen konumsal (iletim hatlarına uzaklık, yollardan uzaklık vb.), topografik (eğim vb.), ekonomik, sosyal ve arazi kullanımı (askeri, tarım vb.) gibi birden çok kritere bağlı olduğu için karmaşık bir süreçtir. $\mathrm{Bu}$ süreç, arazi kullanılabilirliği, altyapının varlığı vb. farklı kriterlerin en uygun kombinasyonunu gerektirmektedir. $\mathrm{Bu}$ sorunları çözmek için genellikle CBS tabanlı çok kriterli karar verme tekniklerinin AHP, Fuzzy, TOPSIS, ELECTRE gibi yöntemlerle birlikte kullanılarak bu süreç yönetilmektedir $[8,25,27,32]$. Bu yöntemlerden güneş enerji santralleri için uygun alanların değerlendirilmesinde kullanılan en yaygın yöntemler AHP ve bulanık mantıktır [29,30,51]. Güneş tesislerine ev sahipliği yapmak için en uygun yerleri bulmada, Sánchez-Lozano, GarcíaCascales [41] Murcia (İspanya)'da, Uyan [22] Karapınar bölgesinde, Carrión, Estrella [47] Granada (İspanya)'da, Asakereh, Soleymani [25] Khuzestan (İran)'da şebekeye bağlı bir enerji santrali kurmak için çevresel, yerel, topografik ve iklimsel faktörlerin dahil edildiği arazilerin uygunluğunun nihai haritasını çıarmak için CBS tabanlı AHP yönteminden faydalanmıştır. Majumdar and Pasqualetti [32]'da çalışmalarında bulanık mantık ve bulanık üyelik fonksiyonları yaklaşımını benimsemiștir. Ancak, diğer çalışmalarla benzer ana faktörleri değerlendirmekle kalmayıp kültürel ve doğa alanlarına mesafeyi halk görüşü olarak ana faktörlerden biri yapması çalışmayı diğer çalışmalardan ayırmıştır. Bu çalışmasında, faktörlerin değerlendirilmesine kamuoyunu dahil ederek güneş enerjisi santrallerinin gelişimi için uygun arazinin mevcudiyeti üzerindeki etkisini anlamaya çalışmıştır. Ek olarak, bu çalışma, gelecekteki arazi örtüsü değişikliklerinin Arizona'da güneş enerji santrallerinin mevcut olan arazi üzerindeki etkisini göstermektedir. Ali, Taweekun [8], Tayland'ın güneyindeki bir eyalet olan Songkhla'da şebeke ölçeğinde rüzgar ve güneş çiftlikleri bulmak için ideal alanları belirlemek için yaptıkları çalışmalarında diğer çalışmalara benzer olarak yüzey özellikleri, çevre ve ekonomi olarak üç ana kriter altında toplamışlardır. Merrouni, Elalaoui [27], Fas'da büyük GES'ler için iklim, topografi, lokasyon ve su kaynağı faktörlerinin dikkate alındığı, CBS tabanlı analizlerin yapıldığ ÇKKV modelinin kombinasyonunu kullanmışlardır.

$\mathrm{Bu}$ çalışmada da güneş santralleri uygun yer seçim kararının verilmesinde CBS çok kriterli analiz yöntemleri uygulanmıştır. Diğer çalışmalarla benzer olarak bu çalışmada da çevresel, ekonomik ve topografik faktörler GES için uygun alanların belirlenmesinde kullanılmıştır. Çevresel faktörler küresel radyasyon değeri, güneş işınım şiddeti ve yıllık güneşlenme süresi olmak üzere doğrudan enerji üretiminin en üst düzeyde olmasını sağlayacak temel özellikleri değerlendirmiştir. Güneşlenme süresi, güneş radyasyonu ile ilişkilendirilmesine rağmen, yapılan çalışmalarda ayrı bir faktör olarak kabul edilmiştir [30,52]. Ana ve alt kriterler uzman görüşü doğrultusunda AHP yöntemi aracılı̆̆ ile ağırlıklandırılmıştır. Çevresel faktörlerin yüksek oranda ağırlığı ile önceki çalışmalarla benzer sonuçların elde edildiği görülmüsstür. Kriterler bulanık mantık aracılığı ile standardize edilmiştir. Çalışma yönteminde belirlenen kriterlerin çakıștırılması sonucunda Mersin İli'nin \%66 gibi büyük bir bölümünün yeni GES için uygun olduğu gözlemlenmiştir. Özellikler eğimin düşük, enerji nakil hatlarına ve 
yerleşim birimlerine yakın ovalık alanlarda konumlanan Tarsus, Yenişehir, Erdemli, Silifke, Mut, Gülnar ilçelerinin ve çevresinin en yüksek uygunluğa sahip olduğu ve bu bölgelerin yenilenebilir enerji potansiyelinin yüksek olduğu görülmüştür. Yenilenebilir Enerji Genel Müdürlüğü, 2014 [53] ülkemizdeki toplam yıllık güneş 1 şınım şiddeti $1,311 \mathrm{kWh} / \mathrm{m}^{2}$, güneşlenme süresi ise 2640 saat olarak belirtilmiştir. Güneş enerjisi santrallerinin verimliliği için en az $4,5 \mathrm{kWh} / \mathrm{m}^{2}$ güneş 1 şınım değeri gerekmektedir [29]. Mersin bölgesinin 1şınım değerlerinin dağlık bölgelerde çok yüksek (1800-2000 kWh/m² yıl) nüfusun yoğun olarak yaşadığı sahil bölgelerinde ise $1700-1750 \mathrm{kWh} / \mathrm{m}^{2}$ yıl'dır. Çalışma alanında yer alan mevcut güneş enerjisi santrallerinin konumları çalışma sonucunda uygun olarak belirlenen alanlarla örtüşmektedir.

Yeni tesis edilmesi planlanan yenilenebilir enerji santrallerinin uygun yer seçim kararının verilmesi multidispliner ve karmaşık bir süreçtir. Bu çalışmada izlenen yöntem güneş santrali konumların seçilmesinde yerel yönetimlere, plan ve politika uygulayıcılara ve karar vericilere bilimsel bir temel sağlamaktadır. $\mathrm{Bu}$ bilgi paydaşların yenilenebilir enerji yatırım yapma konusundaki güvenlerini arttıracak ve gelecek Türkiye'nin fosil yakıta dayalı enerjiye bağımlılığı azaltarak yenilenebilir enerji kaynaklarına yönelik girişimlerine ulaşmanın ayrılmaz bir parçası olacaktır. Fakat uygun alan seçiminde faktörlerin belirlenmesi ülkeden ülkeye, yapılan plan ve projeye ve yönetim stratejilerine bağlı olarak farklılık gösterebilmektedir. Bu yüzden yapılan çalışmalar bölgedeki değişkenler (alan kullanımları, koruma statüleri, kültürel özellikler, vb) dikkate alınarak detaylı bir şekilde incelenmeli ve elektrik şebekesi genişletme planlama verileriyle birlikte değerlendirilmelidir. Böylece çevresel, ekonomik ve sürdürülebilir yer seçim kararı alınmış olacaktır.

\section{KAYNAKLAR}

1. Çolak, M., Kaya, İ., 2017. Prioritization of Renewable Energy Alternatives By Using an Integrated Fuzzy MCDM Model: A Real Case
Application for Turkey. Renewable and Sustainable Energy Reviews, 80, 840-853.

2. Ilbahar, E., Cebi, S., Kahraman, C., 2019. A State-of-the-art Review on Multi-attribute Renewable Energy Decision Making. Energy Strategy Reviews, 25, 18-33.

3. Krishna, K.S., Kumar, K.S., 2015. A Review on Hybrid Renewable Energy Systems. Renewable and Sustainable Energy Reviews, 52, 907-916.

4. International Energy Agency (IEA), World Energy Outlook, https://www.iea.org/reports/world-energyoutlook-2018. 2018.

5. Intergovernmental Panel on Climate Change (IPCC), Special Reports on Renewable Energy Sources. Summary for Policy Makers, in: $11^{\text {th }}$ Session of Working Group III of the IPCC, Abu Dhabi, United Arab Emirates, May 2011. 5-8.

6. IPCC, 2011. Summary for Policymakers. In: IPCC Special Report on Renewable Energy Sources and Climate Change Mitigation [O. Edenhofer, R. Pichs-Madruga, Y. Sokona, K. Seyboth, P. Matschoss, S. Kadner, T. Zwickel, P. Eickemeier, G. Hansen, S. Schlömer, C. von Stechow (eds)], Cambridge University Press, Cambridge, United Kingdom and New York, NY, USA.

7. Rezaei, M., Mostafaeipour, A., Qolipour, M., Reza T.M., 2018. Investigation of the Optimal Location Design of a Hybrid Wind-solar Plant: A Case Study. International Journal of Hydrogen Energy, 43(1), 100-114.

8. Ali, S., Taweekun, J., Techato, K., Waewsak, J., Gyawali, S., 2019. GIS Based Site Suitability Assessment for Wind and Solar Farms in Songkhla, Thailand. Renewable Energy, 132, 1360-1372.

9. Colak, H.E., Memisoglu, T., Gercek, Y., 2020. Optimal Site Selection for Solar Photovoltaic (PV) Power Plants Using GIS and AHP: A Case Study of Malatya Province, Turkey. Renewable Energy, 149, 565-576.

10. Dhar, A., Naeth, M., Jennings, P., Gamal, M., 2020. Perspectives on Environmental Impacts and a Land Reclamation Strategy for Solar and Wind Energy Systems. Science of the Total 
Environment. 718. 134602. 10.1016/j. scitotenv.2019.134602.

11. Dhunny, A.Z., Doorga, J., Allam, Z., Lollchund, M., Boojhawon, R., 2019. Identification of Optimal Wind, Solar and Hybrid Wind-solar Farming Sites Using Fuzzy Logic Modelling. Energy. 188. 116056. 10.1016/j.energy.2019. 116056.

12. Doorga, J.R., Rughooputh, S.D., Boojhawon, R., 2019. Multi-criteria GIS-based Modelling Technique for Identifying Potential Solar Farm Sites: A Case Study in Mauritius. Renewable Energy, 133, 1201-1219.

13. Firozjaei, M.K., Nematollahi, O., Mijani, N., Shorabeh, N.S., Firozjaei, H., Toomanian, A., 2018. An Integrated GIS-based Ordered Weighted Averaging Analysis for Solar Energy Evaluation in Iran: Current Conditions and Future Planning. Renewable Energy. 136, 1130-1146. 10.1016/j.renene.2018.09.090.

14. T.C. Enerji ve Tabii Kaynaklar Bakanlığ (MENR). Ministry of Energy and Natural Resources. Solar, https://www.enerji.gov.tr/enUS/Pages/Solar. 2019 [cited 20201 March ].

15. Gorgulu, S., 2019. Investigation of Renewable Energy Potential and Usage in TR 61 Region. Journal of Cleaner Production, 236, 117698.

16. Toklu, E., 2013. Overview of Potential and Utilization of Renewable Energy Sources in Turkey. Renewable Energy, 50, 456-463.

17.T.C. Enerji ve Tabii Kaynaklar Bakanlığ (MENR). 2019. Ministry of Energy and Natural Resources. General Directorate of Energy Affair, https://www.eigm.gov.tr/trTR/Enerji-Politikalari. [cited 202014 May].

18. Regulatory, R.O.T.E.M. Electricity Market Sector Report, 2018, https://www.epdk.org.tr/Detay/Icerik/3-024/elektrikyillik-sektor-raporu. 2020 [cited 202015 May].

19. Çukurova Kalkınma Ajansı, 2020. The Çukurova Regional Development Agency, 2014-2023 Çukurova Regional Plan, https://www.kalkinmakutuphanesi.gov.tr/doku man/2014-2023-cukurova-bolge-plani/1149. [cited 202015 May].

20. Türkiye Elektrik İletim Anonim Şirketi (TEIAS) 2019. Turkish Electricity Transmission Corporation. Installed Capacity
Report, https://www.teias.gov.tr/tr-TR/turkiyeelektrik-uretim-iletim-istatistikleri, [cited 2019 1 February ].

21. Koc, A., Turk, S., Şahin, G., 2019. Multicriteria of Wind-solar Site Selection Problem Using a GIS-AHP-based Approach with an Application in Igdir Province/Turkey. Environmental Science and Pollution Research, 26(31), 32298-32310.

22. Uyan, M., 2013. GIS-based Solar Farms Site Selection Using Analytic Hierarchy Process (AHP) in Karapinar Region, Konya/Turkey. Renewable and Sustainable Energy Reviews, 28, 11-17.

23. Yelmen, B., Çakir, M.T., 2016. Influence of Temperature Changes in Various Regions of Turkey on Powers of Photovoltaic Solar Panels. Energy Sources, Part A: Recovery, Utilization, and Environmental Effects, 38(4), 542-550.

24. Al Garni, H.Z., Awasthi, A., 2017. Solar PV Power Plant Site Selection Using a GIS-AHP Based Approach with Application in Saudi Arabia. Applied Energy, 206, 1225-1240.

25. Asakereh, A., Soleymani, M., Sheikhdavoodi, M.J., 2017. A GIS-based Fuzzy-AHP Method for the Evaluation of Solar Farms Locations: Case Study in Khuzestan Province, Iran. Solar Energy, 155, 342-353.

26. Yushchenko, A., de Bono, A., Chatenoux, B., Kumar, P.M., Ray, N., 2018. GIS-based Assessment of Photovoltaic (PV) and Concentrated Solar Power (CSP) Generation Potential in West Africa. Renewable and Sustainable Energy Reviews, 81, 2088-2103.

27. Merrouni, A.A., Elalaoui, F.E., Mezrhab, A., Mezrhab, A., Ghennioui, A., 2018. Large Scale PV Sites Selection by Combining GIS and Analytical Hierarchy Process. Case Study: Eastern Morocco. Renewable Energy,119, 863-873.

28. Thapar, V., 2019. A Revisit to Solar Radiation Estimations Using Sunshine Duration: Analysis of Impact of These Estimations on Energy Yield of a PV Generating System. Energy Sources, Part A: Recovery, Utilization, and Environmental Effects, 1-25.

29. Aydin, N.Y., Kentel, E., Duzgun, H.S., 2013. GIS-Based Site Selection Methodology for 
Hybrid Renewable Energy Systems: A Case Study from Western Turkey. Energy Conversion and Management, 70, 90-106.

30. Doljak, D., Stanojević, G., 2017. Evaluation of Natural Conditions for Site Selection of Ground-mounted Photovoltaic Power Plants in Serbia. Energy, 127, 291-300.

31. Ozdemir, S., Sahin, G., 2018. Multi-criteria decision-making in the Location Selection for a Solar PV Power Plant Using AHP. Measurement, 129, 218-226.

32. Majumdar, D., Pasqualetti, M.J., 2019. Analysis of Land Availability for Utility-scale Power Plants and Assessment of Solar Photovoltaic Development in the State of Arizona, USA. Renewable Energy, 134, 1213-1231.

33. Commission, T.W.D., 2010. WDC, Site Options for Concentrated Solar Power Generation in the Wheatbelt Final Report.

34. Charabi, Y., Gastli, A., 2011. PV Site Suitability Analysis Using GIS-based Spatial Fuzzy Multi-criteria Evaluation. Renewable Energy, 36(9), 2554-2561.

35. Merrouni, A.A., Mezrhab, A., Mezrhab, A., 2016. PV Sites Suitability Analysis in the Eastern Region of Morocco. Sustainable Energy Technologies and Assessments, 18, 6-15.

36. Noorollahi, Y., Yousefi, H., Mohammadi, M., 2016. Multi-criteria Decision Support System for Wind Farm Site Selection Using GIS. Sustainable Energy Technologies and Assessments, 13, 38-50.

37. Giamalaki, M., Tsoutsos, T., 2019. Sustainable Siting of Solar Power Installations in Mediterranean Using a GIS/AHP Approach. Renewable Energy, 141, 64-75.

38. Tsoutsos, T., Frantzeskaki, N., Gekas, V., 2005. Environmental Impacts from the Solar Energy Technologies. Energy Policy, 33(3), 289-296.

39. Anwarzai, M.A., Nagasaka, K., 2017. Utilityscale Implementable Potential of Wind and Solar Energies for Afghanistan Using GIS Multi-criteria Decision Analysis. Renewable and Sustainable Energy Reviews, 71, 150-160.

40. Aly, A., Jensen, S.S., Pedersen, A.B., 2017. Solar Power Potential of Tanzania: Identifying
CSP and PV Hot Spots Through a GIS Multicriteria Decision Making Analysis. Renewable Energy, 113, 159-175.

41. Sánchez-Lozano, J.M., García-Cascales, M.S., Lamata, M.T., 2015. Evaluation of Suitable Locations for the Installation of Solar Thermoelectric Power Plants. Computers \& Industrial Engineering, 87, 343-355.

42. Tahri, M., Hakdaoui, M., Maanan, M., 2015. The Evaluation of Solar Farm Locations Applying Geographic Information System and Multi-Criteria Decision-Making methods: Case Study in Southern Morocco. Renewable and Sustainable Energy Reviews, 51, 1354-1362.

43. Baban, S.M., Parry, T., 2001. Developing and Applying a GIS-assisted Approach to Locating Wind Farms in the UK. Renewable Energy, 24(1), 59-71.

44. Watson, J.J., Hudson, M.D., 2015. Regional Scale Wind Farm and Solar Farm Suitability Assessment Using GIS-assisted Multi-criteria Evaluation. Landscape and Urban Planning, 138, 20-31.

45. Tavana, M., Santos, A., Francisco, J., Mohammadi, S., Alimohammadi, M., 2017. A Fuzzy Multi-Criteria Spatial Decision Support System for Solar Farm Location Planning. Energy Strategy Reviews. 18. 93-105. 10.1016/j.esr.2017.09.003.

46. Yun-na, W., Yisheng, Y., Tiantian, F., Li-na, K., Wei, L., Luo-jie, F., 2013. Macro-site Selection of Wind/solar Hybrid Power Station Based on Ideal Matter-Element Model. International Journal of Electrical Power \& Energy Systems. 50(1), 76-84. 10.1016/j.ijepes.2013.02.024.

47. Carrión, J., Estrella, A., Dols, F., Zamorano, M., Rodríguez, M., Ridao, A., 2008. Environmental Decision-support Systems for Evaluating the Carrying Capacity of Land Areas: Optimal Site Selection for Gridconnected Photovoltaic Power Plants. Renewable and Sustainable Energy Reviews. 12(9), 2358-2380. 10.1016/j.rser.2007.06.011.

48. Ziuku, S., Seyitini, L., Mapurisa, B., David, C., Kuijk, K., 2014. Potential of Concentrated Solar Power (CSP) in Zimbabwe. Energy for Sustainable Development, 23, 220-227. 
49. Unal, M., Cilek, A., Guner, E.D., 2019. Implementation of Fuzzy, Simos and Strengths, Weaknesses, Opportunities and Threats Analysis for Municipal Solid Waste Landfill Site Selection: Adana City Case Study. Waste Management \& Research, 0734242 X19893111.

50. Kandel, A., 1980. The Analytic Hierarchy Process-Planning, Priority Setting, Resource Allocation, Thomas L. Saaty (Ed.), McGrawHill, Basel, 1983, North-Holland, 287.

51. García-Cascales, M.S., Sánchez-Lozano, J.M.. 2013. Geographical Information Systems (GIS) and Multi-Criteria Decision Making (MCDM) Methods for the Evaluation of Solar Farms Locations: Case Study in South-eastern Spain. Renewable and Sustainable Energy Reviews. 24. 544. 10.1016/j.rser.2013.03.019.

52. Zoghi, M., Ehsani, A., Sadat, M., Amiri, M., Karimi, S., 2015. Optimization Solar Site Selection by Fuzzy Logic Model and Weighted Linear Combination Method in Arid and Semiarid Region: A Case Study Isfahan-IRAN. Renewable and Sustainable Energy Reviews. 68(1), 986-996.

53. Yenilenebilir Enerji Genel Müdürlüğü. General Directorate of Energy Affairs. Solar Energy Potential Atlas, http://www.yegm.gov.tr /MyCalculator/. 2020 [cited 202012 May]. 